\title{
Associations of Total Serum IgE and Peripheral Blood Eosinophils with Childhood Asthma: a Longitudinal Retrospective Study
}

\author{
JYH-HONG LEE ( $\sim$ leonid@ntu.edu.tw) \\ National Taiwan University Hospital https://orcid.org/0000-0003-4285-4912 \\ Ai-Lin Chu \\ National Taiwan University Hospital \\ Shu-Ya Hsiao \\ National Taiwan University Hospital \\ Kuei-Ying Chang \\ National Taiwan University Hospital \\ Yao-Hsu Yang \\ National Taiwan University Hospital \\ Yu-Tsan Lin \\ National Taiwan University Hospital \\ Li-Chieh Wang \\ National Taiwan University Hospital \\ Hsin-Hui Yu \\ National Taiwan University Hospital \\ Ya-Chiao Hu \\ National Taiwan University Hospital \\ Bor-Luen Chiang \\ National Taiwan University Hospital
}

\section{Research}

Keywords: asthma, eosinophil, immunoglobulin E, microRNA, time

Posted Date: October 1st, 2020

DOI: https://doi.org/10.21203/rs.3.rs-84082/v1

License: (1) (1) This work is licensed under a Creative Commons Attribution 4.0 International License.

Read Full License 


\section{Abstract}

\section{Background}

Childhood asthma is a heterogeneous disease. The relationship of total serum IgE and peripheral blood eosinophil with childhood asthma are controversial. To determine whether total serum IgE and peripheral blood eosinophil are associated with long-term lung function, asthma severity and asthma control in children.

\section{Methods}

We conducted a longitudinal retrospective study in 383 childhood asthma patients with total serum IgE and peripheral blood eosinophil obtained at baseline. Peak expiratory flow (PEF) variability, predicted PEF percentage, asthma severity, asthma control test (ACT) score, and asthma control from each follow-up visit were recorded as phenotype outcomes. We correlated serum IgE and blood eosinophil with phenotype outcomes using generalized estimating equations. Additionally, we compared expression of microRNA in peripheral blood cells from nonallergic versus allergic patients.

\section{Results}

Total serum IgE was positively associated with asthma severity $(\mathrm{OR}=1.0014, P=0.0071)$. Peripheral blood eosinophil was positively related to PEF variability $(O R=1.0052, P=0.0002)$. Association of inhaled corticosteroids (ICS) dose with phenotype outcomes were not significant. Compared with allergic patients, children with nonallergic asthma had higher asthma severity. We identified six interaction pathways specific to IgE from eight top differentially expressed microRNAs.

\section{Conclusions}

Beside asthma control, total serum lgE is predictive of long-term asthma severity and peripheral blood eosinophil is closely related to PEF variability. We suggest that total serum IgE might be involved in modulating disease severity of both allergic and nonallergic asthma while peripheral blood eosinophilia reflects the status of longitudinal lung function.

\section{Introduction}

Childhood asthma is a heterogeneous disease with multiple factors, complex pathophysiologic mechanisms, and diverse clinical and molecular phenotypes (1). The major focus of asthma investigations is on the underlying immunoglobulin $\mathrm{E}(\mathrm{IgE})$-mediated inflammatory mechanisms. The total serum IgE tends to be higher in adults and children with allergic diseases compared to nonallergic individuals. Marsh et al. calculated that the optimal total serum IgE levels for discriminating between allergic and nonallergic adults was $100 \mathrm{IU} / \mathrm{mL}$; however, this cut-off misclassified approximately $20 \%$ of each group (2). 
Th2-high asthma is characterized by exaggerated airway hyperresponsiveness, high total serum IgE, and peripheral blood eosinophilia (3). Total serum IgE is related to the severity of atopy in allergic diseases (4). In children, however, there are conflicting results regarding the relationship of asthma severity with total serum IgE. Some works show that the total serum IgE determines atopy but not its severity (5), whereas others report a positive correlation between total serum IgE and asthma severity in children under 16 years of age (6-13). IgE might play a role in modulating asthma severity.

Serial measurements of the peripheral blood eosinophil count correlate with asthma severity, and can be used for monitoring changes therein (14-16). Blood eosinophilia is also observed in pediatric asthma and is related to disease severity (17). However, it has also been reported that the blood eosinophil count is not correlated with the airway eosinophil count in children with severe asthma (18). Few studies of the association of asthma severity with peripheral blood eosinophils have involved pediatric patients.

Studies attempting to identify childhood asthma phenotypes are hampered by the fact that most studies characterized patients at a single time point (19). Furthermore, it is not clear whether controller therapy has been optimized based on guidelines and that compliance with treatment has been carefully assessed (12). Furthermore, the majority of children with persistent asthma exhibit abnormal pulmonary function only during acute exacerbations. Children can have severe exacerbations despite limited symptoms and normal lung function before the event and medications may be discontinued (9). Characterization of asthma severity and/or asthma control in pediatric patients should consider these observations.

In this study, we used the predicted peak expiratory flow (PEF) percentage and PEF variability for lung function evaluation of pediatric patients. Also, we used the asthma severity, asthma control test (ACT) score, and asthma control as markers of childhood asthma phenotype. We attempted to determine whether total serum IgE and peripheral blood eosinophil affect the lung function, degree of asthma severity and level of asthma control. Finally, we measured the patterns of change (trends) in the childhood asthma phenotype during a long-term follow-up.

\section{Methods}

Improvement plan for health care benefits of asthma (National Health Insurance, Taiwan)

In September 2004, National Taiwan University Hospital joined this program. The program introduces incentives to improve the quality of asthma care, encourages hospitals to engage in patient-centered complete asthma care, improves compliance with guidelines, strengthens follow-up visits and healtheducation services for asthmatic patients, and ensures the provision of complete and continuous care.

\section{Inclusion criteria}

The enrolled patients were diagnosed with asthma (ICD-9-CM 493 or ICD-10-CM J44-J45) within 90 days before enrollment by the same physician and had completed at least two outpatient visits to that 
physician. The patients were willing to comply with asthma care regulations and with follow-up contacts by our asthma case managers.

\section{End of enrollment}

1. Completion of self-care and self-evaluation (disease resolved).

2. Refusal by the patient of further contact by asthma case managers and/or follow-up by asthma specialists.

3. Loss of contact and/or follow-up for $>90$ days.

4. Change in place of residence.

5. Death.

6. Noncompliance with the program regulations for $>1$ year.

7. Others (e.g., transfer to other care provider, change in diagnosis).

These patients continued to receive medications and treatments for their asthma as indicated by their asthma specialist and guided by the Global Initiative for Asthma (GINA) (20). These patients were required to receive care and follow-up from their physician for at least 3 months. The data were collected at baseline (total serum IgE and blood eosinophil percentage) and clinical data were collected by asthma case managers during interviews and follow-up visits.

These enrolled patients were provided comprehensive information on asthma care, including the pathophysiology of asthma, how to diagnose asthma, asthma severity, environmental allergens and control, management of acute attacks, long-term control of asthma, asthma relievers and controllers, and the importance of monitoring PEF. We instructed the patients in the correct method of inhalation, the timing of medications, and measurement of the peak PEF at home.

The following parameters were recorded at each outpatient visit: (1) tracking/visit date, (2) frequency of daytime symptoms, (3) frequency of nighttime symptoms, (4) predicted PEF (best \%) (5) PEF variability (\%), (6) asthma severity assessment, (7) ACT/CACT score (21), and (8) asthma control. The asthma severity classification, asthma control classification, and PEF variability and predicted percentage were defined according to the Guidelines for the Diagnosis and Management of Asthma (EPR-3)(22). Children with uncontrolled asthma according to the GINA criteria are likely to be clinically different from those included in studies using a C-ACT or ACT score of $<20$ as a criterion to define uncontrolled asthma (23). Therefore, we used both the CACT/ACT score and the GINA criteria to evaluate the level of asthma control in children.

\section{Patients}

From September 1, 2004 to December 31, 2018 we registered 1115 eligible children. Among them, 383 children with information on total serum IgE and peripheral blood eosinophil percentage (independent 
variables) were enrolled. Another 313 children with only peripheral blood eosinophil percentage (independent variables) were also enrolled. PEF variability, predicted PEF (best percentage), asthma severity, ACT score, and asthma control during the follow-up of these 692 patients were collected as phenotype outcomes (dependent variables). Asthma and rhinitis were optimally managed by study physicians according to the applicable guidelines.

Descriptive statistics were calculated for demographic and baseline characteristics. IgE values in excess of $5000 \mathrm{IU} / \mathrm{mL}$ were assigned a value of $5000 \mathrm{IU} / \mathrm{mL}$. The geometric mean (GM) and the arithmetic mean (AM) were calculated to approximate the normal distribution for statistical inference and modeling. Patients were classified as allergic if their total serum lgE level was ${ }^{3} 150 \mathrm{IU} / \mathrm{mL}$ and as nonallergic if their total serum IgE level was $<150 \mathrm{IU} / \mathrm{mL}(7)$.

\section{Sensitization}

Thirty six allergen-specific IgE (slgEs) were grouped into the following seven categories: dust mites (house dust mite, farinae mite, pterony mite), danders/feathers (chicken feather, cat, dog), molds (Alternaria, Aspergillus, Cladosporium, Penicillium), grasses/trees (Bermuda grass, Willow black, Eucalyptus, Cedar Japan, mulberry mix, pigweed mix, ragweed mix, Timothy grass), foods (avocado, pork, beef, milk, cheddar cheese, shrimp, crab, clam, cod, tuna, peanut, soybean, wheat, brewer yeast, egg yolk, egg white), cockroach mix, and latex.

\section{Peak expiratory flow (PEF)}

We measured PEF variability and predicted percentage according to the Guidelines for the Diagnosis and Management of Asthma (EPR-3)(22). Individual peak flow measurements are highly variable and the PEF variability has greater predictive power for future exacerbations than individual PEF measurements (24).

\section{Sequencing of miRNAs with RNA-seq}

Peripheral blood samples were obtained from four nonallergic and five allergic asthmatic patients. Total RNA was extracted from peripheral blood white blood cells using the miRNeasy Extraction Kit (Qiagen) according to the manufacturer's protocol. Sequencing was performed using high-quality RNA with RNA integrity number $(R I N) \geq 7$. A total of $1.2 \mu \mathrm{g}$ of total RNA per sample was used as input material for the small RNA library. Sequencing libraries were generated using the TruSeq Small RNA Library Prep Kit (Illumina) following the manufacturer's recommendations and index codes were added to attribute sequences to the samples. Briefly, 3 '- and 5 '-adapters were specifically ligated to the 3 '- and 5 '-ends of small RNAs. Next, first-strand cDNA was synthesized using SuperScript II Reverse Transcriptase. PCR amplification was performed using 2' PCR Master Mix and the PCR products were resolved in a BluePippin 3\% agarose gel. DNA fragments of $120-160$ bp were recovered and dissolved in $15 \mu \mathrm{L}$ of 
double-distilled water. Library quality was assessed using the Agilent Bioanalyzer 2100 system and DNA High-Sensitivity Chips. The libraries were sequenced on the Illumina NextSeq 500 platform and 75-bp single-end reads were generated. MiRNA expression levels were expressed as RPM (reads per million). The heat map were generated by uploading the differential expressed miRNAs data to ClustVis (https://biit.cs.ut.ee/clustvis/).

Ingenuity pathway analysis

miRNA expression profiles were analyzed by ingenuity pathway analysis (IPA), using the features core analysis and pathway explore. Finally, the direct interaction pathway and the node and target molecules were overlaid with the differentially expressed miRNAs between allergic and nonallergic asthma to plot the network diagram.

\section{Statistical analysis}

Generalized estimating equations (GEEs) are important in the analysis of correlated data (25). These data sets can be generated in longitudinal studies, in which patients are measured at different points in time, or from clustering, in which measurements are taken of patients who share a common characteristic. We performed GEE analysis using the GENMOD and GEE procedures in SAS software. Missing data are common in longitudinal studies and can be caused by dropouts or skipped visits. Both procedures implement the standard GEE approach for longitudinal data; this approach is appropriate for complete data or when data are missing completely at random.

We first analyzed the association between independent variables and dependent variables (phenotype outcome). The independent variables were total serum IgE level (original value divided by 100), peripheral blood eosinophil percentage, and inhaled corticosteroid (ICS) dosage (low, medium, and high). Low, medium, and high daily doses of inhaled corticosteroids (ICS) of estimated comparability were defined by GINA (20). The dependent variables were predicted PEF, PEF variability, ACT score, asthma severity, and asthma control. All outcome variables were measured at different occasions (e.g., time points/visits), so time was considered a covariate of the independent variables (total serum IgE level and blood eosinophil percentage) to determine the time effect. That is, the numbers of time points/visits were conceptually equivalent to disease duration. The interaction terms were total serum $\lg \mathrm{E} *$ time and blood eosinophil * time. We took the time factor into consideration and analyzed the association between independent variables and dependent variables under the interaction between time and the independent variables.

\section{Odds ratio and beta coefficient}

The odds ratio (OR) quantifies the strength of the association between an outcome (dependent variable) and a change (independent variable). An OR of $<1$ indicates lower odds that an outcome is attributed to a of change; and an OR of $>1$ indicates higher odds that an outcome is attributed to a change. 
The beta coefficient is the degree of change in the dependent variable for each unit of change in the independent variable. The beta coefficient can be negative or positive. If the beta coefficient is not statistically significant, the independent variable is not significantly predictive of the dependent variable (outcome). If the beta coefficient is positive, for each unit of increase in the independent variable, the outcome will increase by the beta-coefficient value. If the beta coefficient is negative, for each unit increase in the independent variable, the outcome variable will decrease by the beta-coefficient value.

\section{Longitudinal outcome pattern analysis}

To evaluate the longitudinal trends of childhood asthma, we divided 383 patients into $\mathrm{lgE}<150 \mathrm{IU} / \mathrm{mL}$ ( $\mathrm{n}$ $=118), \lg E 150-550 \mathrm{IU} / \mathrm{mL}(\mathrm{n}=133)$, and $\lg \mathrm{P}>550 \mathrm{IU} / \mathrm{mL}(\mathrm{n}=132)$ groups. Among these three group of patients, we selected patients with a follow-up duration of more than 5 years for pattern analysis. Locally weighted scatterplot smoothing (LOWESS) in Prism version 8 (GraphPad Software) enabled fitting of a curve without selecting a model (26). We plotted follow-up duration against asthma severity changing with time for the patients received followed-up for more than 5 years.

\section{Results}

\section{Patients' characteristics and average phenotype outcomes}

The demographic characteristics, average asthma severity, average asthma control level, sensitization status, and comorbidities (AR and/or AD) of the 383 patients are listed in Table 1. In adults, it has been reported that nonallergic asthma has a later age of onset than allergic asthma (27). However, the average age at enrollment of nonallergic asthmatic children was significantly younger than that of children with allergic asthma. The most common asthma severity was intermittent to mild persistent severity (79.38\%). The most frequent level of asthma control was partially well controlled (55.65\%). Most patients were sensitized to mites (78.59\%) and concurrently suffered from AR (53.0\%). 
Table 1

Descriptive characteristics of 383 patients with childhood asthma.

\begin{tabular}{|c|c|c|c|}
\hline & $\begin{array}{l}\text { Total } \\
\text { subject } \\
(n=383)\end{array}$ & $\begin{array}{l}\text { Subjects of } \operatorname{lgE}< \\
150 \mathrm{IU} / \mathrm{mL}(\mathrm{n}=118)\end{array}$ & $\begin{array}{l}\text { Subjects of } \operatorname{lgE} \geq \\
150 \mathrm{IU} / \mathrm{mL}(\mathrm{n}=265)\end{array}$ \\
\hline $\begin{array}{l}\text { Age at enrollment, } \\
\text { mean } \pm S D \text { (range) }\end{array}$ & $\begin{array}{l}6.204 \pm \\
2.925 \\
(1.42- \\
17.0)\end{array}$ & $\begin{array}{l}5.329 \pm 2.537 \\
(1.42-14.13)^{*}\end{array}$ & $\begin{array}{l}6.590 \pm 3.006 \\
(1.42-17.0)\end{array}$ \\
\hline F:M (ratio) & $\begin{array}{l}160: 223 \\
(0.72)\end{array}$ & $52: 66(0.79)$ & 108:157 (0.69) \\
\hline $\begin{array}{l}\text { Average asthma severity } \dagger \\
(\text { mean } \pm S D)\end{array}$ & $\begin{array}{l}1.866 \pm \\
0.4581\end{array}$ & $1.899 \pm 0.4661$ & $1.851 \pm 0.4547$ \\
\hline severity types $(n, \%)$ & 383 & 118 & 265 \\
\hline intermittent & $18(4.70)$ & $6(5.08)$ & $12(4.53)$ \\
\hline > intermittent & $\begin{array}{l}150 \\
(39.16)\end{array}$ & $39(33.05)$ & $111(41.89)$ \\
\hline mild persistent & $\begin{array}{l}154 \\
(40.21)\end{array}$ & $50(42.37)$ & $104(39.25)$ \\
\hline$>$ mild persistent & $33(8.62)$ & $15(12.71)$ & $18(6.79)$ \\
\hline moderate persistent & $27(7.05)$ & $8(6.78)$ & $19(7.17)$ \\
\hline$>$ moderate persistent & $1(0.26)$ & $0(0)$ & $1(0.26)$ \\
\hline $\begin{array}{l}\text { Average asthma controlł } \\
\text { (mean } \pm S D)\end{array}$ & $\begin{array}{l}1.606 \pm \\
0.3733\end{array}$ & $1.706 \pm 0.4382$ & $1.564 \pm 0.3349$ \\
\hline control types $(n, \%)$ & 239 & 71 & 168 \\
\hline well controlled & $\begin{array}{l}30 \\
(12.55)\end{array}$ & $8(11.27)$ & $22(13.10)$ \\
\hline$<$ well controlled & $\begin{array}{l}133 \\
(55.65)\end{array}$ & $35(49.30)$ & $98(58.33)$ \\
\hline
\end{tabular}

$* P<0.05$

† Asthma severity were classified as: intermittent (1 point), mild persistent ( 2 point), moderate persistent (3 point), and severe persistent (4 point).

¥ Asthma control were classified as: well controlled (1 point), not well controlled ( 2 point) and very poorly controlled (3 point).

$\S$ AM: arithmetic mean; GM: geometric mean 


\begin{tabular}{|c|c|c|c|}
\hline & $\begin{array}{l}\text { Total } \\
\text { subject } \\
(n=383)\end{array}$ & $\begin{array}{l}\text { Subjects of } \mathrm{lgE}< \\
150 \mathrm{IU} / \mathrm{mL}(n=118)\end{array}$ & $\begin{array}{l}\text { Subjects of } \mathrm{lgE} \geq \\
150 \mathrm{IU} / \mathrm{mL}(\mathrm{n}=265)\end{array}$ \\
\hline not well controlled & $\begin{array}{l}67 \\
(28.03)\end{array}$ & $22(30.99)$ & $45(26.79)$ \\
\hline$<$ not well controlled & $4(1.67)$ & $3(4.23)$ & $1(0.60)$ \\
\hline very poorly controlled & $5(2.09)$ & $3(4.23)$ & $2(1.19)$ \\
\hline $\begin{array}{l}\text { Total serum IgE, AM } \pm S D \\
(I U / m L) \S\end{array}$ & $\begin{array}{l}655.7 \pm \\
912.9\end{array}$ & $64.72 \pm 45.35$ & $918.9 \pm 989.6$ \\
\hline $\begin{array}{l}\text { Total serum IgE, GM } \pm \text { SD } \\
(\mathrm{IU} / \mathrm{mL}) \S\end{array}$ & $\begin{array}{l}278.2 \pm \\
4.447\end{array}$ & $45.77 \pm 2.630$ & $621.3 \pm 2.314$ \\
\hline $\begin{array}{l}\text { Peripheral blood eosinophil, } \\
\text { mean } \pm S D(\%)\end{array}$ & $\begin{array}{l}5.171 \pm \\
4.242\end{array}$ & $3.365 \pm 2.466$ & $5.962 \pm 4.603$ \\
\hline \multicolumn{4}{|l|}{ Sensitization status (n, \%) } \\
\hline dust mites & $\begin{array}{l}301 \\
(78.59 \%)\end{array}$ & $48(40.68 \%)$ & $253(95.47 \%)$ \\
\hline danders & $\begin{array}{l}72 \\
(18.80 \%)\end{array}$ & $9(7.63 \%)$ & $63(23.77 \%)$ \\
\hline molds & $\begin{array}{l}17 \\
(4.44 \%)\end{array}$ & $2(1.69 \%)$ & $15(5.66 \%)$ \\
\hline grass & $\begin{array}{l}15 \\
(3.92 \%)\end{array}$ & $1(0.85 \%)$ & $14(5.28 \%)$ \\
\hline foods & $\begin{array}{l}150 \\
(39.16 \%)\end{array}$ & $17(14.41 \%)$ & 133 (50.19\%) \\
\hline cockroach & $\begin{array}{l}89 \\
(23.24 \%)\end{array}$ & $7(5.93 \%)$ & $82(30.94 \%)$ \\
\hline latex & $1(0.26 \%)$ & $1(0.85 \%)$ & $0(0 \%)$ \\
\hline \multicolumn{4}{|l|}{ Comorbidity, No. (n, \%) } \\
\hline AR & $\begin{array}{l}203 \\
(53.0 \%)\end{array}$ & $70(59.32 \%)$ & $133(50.19 \%)$ \\
\hline
\end{tabular}

* $P<0.05$

† Asthma severity were classified as: intermittent (1 point), mild persistent ( 2 point), moderate persistent (3 point), and severe persistent (4 point).

‡ Asthma control were classified as: well controlled (1 point), not well controlled ( 2 point) and very poorly controlled (3 point).

$\S$ AM: arithmetic mean; GM: geometric mean 


\begin{tabular}{|c|c|c|c|}
\hline & $\begin{array}{l}\text { Total } \\
\text { subject } \\
(n=383)\end{array}$ & $\begin{array}{l}\text { Subjects of } \operatorname{lgE}< \\
150 \mathrm{IU} / \mathrm{mL}(\mathrm{n}=118)\end{array}$ & $\begin{array}{l}\text { Subjects of } \operatorname{lgE} \geq \\
150 \mathrm{IU} / \mathrm{mL}(\mathrm{n}=265)\end{array}$ \\
\hline$A D$ & $\begin{array}{l}11 \\
(2.87 \%)\end{array}$ & $3(2.54 \%)$ & $8(3.02 \%)$ \\
\hline$A R+A D$ & $\begin{array}{l}116 \\
(30.29 \%)\end{array}$ & $24(20.34 \%)$ & $92(34.72 \%)$ \\
\hline Nil (asthma only) & $\begin{array}{l}53 \\
(13.84 \%)\end{array}$ & $21(17.80 \%)$ & $32(12.07 \%)$ \\
\hline \multicolumn{4}{|l|}{$\star P<0.05$} \\
\hline \multicolumn{4}{|c|}{$\begin{array}{l}\text { † Asthma severity were classified as: intermittent ( } 1 \text { point), mild persistent ( } 2 \text { point), moderate } \\
\text { persistent ( } 3 \text { point), and severe persistent ( } 4 \text { point). }\end{array}$} \\
\hline \multicolumn{4}{|c|}{$\begin{array}{l}\text { ‡ Asthma control were classified as: well controlled ( } 1 \text { point), not well controlled ( } 2 \text { point) and very } \\
\text { poorly controlled ( } 3 \text { point). }\end{array}$} \\
\hline \multicolumn{4}{|c|}{$\S$ AM: arithmetic mean; GM: geometric mean } \\
\hline
\end{tabular}

Correlation between total serum IgE levels and peripheral blood eosinophil percentages

By Pearson correlation analysis, we found a significantly moderate correlation between total serum IgE level and peripheral blood eosinophil percentage (Fig. 1; Pearson's $r=0.34725, P<0.0001$ ). This is in agreement with Haughney et al., who reported a weak correlation between serum IgE level and blood eosinophil percentage (correlation coefficient $=0.276, P<0.001$ ) (28).

\section{Associations of total serum IgE level and peripheral blood eosinophil percentage with phenotype outcomes}

A preliminary association analysis using the GEE method (supplemental Table 1) showed that, except for ACT score, most phenotype outcomes were not significantly related to serum total IgE level or blood eosinophil percentage. The ACT score was positively related to total serum IgE in a univariate analysis $(\mathrm{OR}=1.0373 ; P=0.0035)$ and in a multivariate analysis after controlling for peripheral blood eosinophil percentage ( $O R=1.0438 ; P=0.0014)$. The ACT score was positively associated with the peripheral blood eosinophil percentage only in a univariate analysis $(\mathrm{OR}=1.0081 ; P<0.0001)$. Arango et al. reported that the ACT score is negatively correlated with the absolute eosinophil count (29). Here, the ACT score was negatively associated with the blood eosinophil percentage in a multivariate analysis $(\mathrm{OR}=0.9749 ; P=$ 0.4170). Rosario et al. reported that eosinophil count is not correlated to asthma severity, in consistent with our findings (30).

Taking the time (disease duration) effect into account (Table II), the blood eosinophil percentage was negatively associated with PEF variability $(O R=0.9119, P=0.0011)$. When the interactions between time 
effects and peripheral blood eosinophil percentage (Table 2; eosinophil $*$ time) were considered, the risk of higher PEF variability increased 1.0052-fold $(P=0.0002)$. Therefore, during follow-up, the higher the blood eosinophil percentage, the higher the PEF variability (risk effect). Indeed, the peripheral blood eosinophil count is reportedly significantly positively correlated with PEV variability in childhood asthma (31). 
Table 2

The association (ORs and beta coefficient) of total serum IgE level and blood eosinophil percentage with phenotype outcomes under taking the time (disease duration) effect into account.

\begin{tabular}{|c|c|c|}
\hline Outcome/variables & OR $(95 \% \mathrm{Cl})$ & $P$-value \\
\hline \multicolumn{3}{|l|}{ Predicted PEF percentage } \\
\hline $\lg \mathrm{E}$ & $0.9933(0.97,1.02)$ & 0.6285 \\
\hline $\lg \mathrm{E} *$ Time & $1.0006(0.99,1.00)$ & 0.5400 \\
\hline peripheral blood Eosinophil percentage & $0.9961(0.95,1.05)$ & 0.8845 \\
\hline peripheral blood Eosinophil percentage * Time & $0.9993(0.99,1.00)$ & 0.6967 \\
\hline Time & $0.9945(0.98,1.01)$ & 0.5798 \\
\hline \multicolumn{3}{|l|}{ PEF variability } \\
\hline $\lg \mathrm{E}$ & $1.0016(0.97,1.03)$ & 0.9092 \\
\hline $\lg \mathrm{E} *$ Time & $0.9997(0.99,1.00)$ & 0.6659 \\
\hline peripheral blood Eosinophil percentage & $0.9119(0.86,0.96)$ & 0.0011 \\
\hline peripheral blood Eosinophil percentage * Time & $1.0052(1.00,1.01)$ & 0.0002 \\
\hline Time & $1.0030(0.98,1.02)$ & 0.7740 \\
\hline \multicolumn{3}{|l|}{ Asthma severity } \\
\hline $\lg \mathrm{E}$ & $0.9872(0.97,1.00)$ & 0.0693 \\
\hline $\lg \mathrm{E} *$ Time & $1.0014(1.00,1.01)$ & 0.0071 \\
\hline peripheral blood Eosinophil percentage & $0.9774(0.94,1.01)$ & 0.2059 \\
\hline peripheral blood Eosinophil percentage * Time & $1.0012(0.99,1.01)$ & 0.3553 \\
\hline Time & $0.9975(0.98,1.02)$ & 0.7804 \\
\hline \multicolumn{3}{|l|}{ Asthma control } \\
\hline $\lg \mathrm{E}$ & $0.9909(0.97,1.02)$ & 0.4688 \\
\hline $\lg \mathrm{E} *$ Time & $1.0009(1.00,1.01)$ & 0.0124 \\
\hline peripheral blood Eosinophil percentage & $1.0758(1.03,1.13)$ & 0.0019 \\
\hline peripheral blood Eosinophil percentage * Time & $0.9968(0.99,0.99)$ & 0.0068 \\
\hline Time & $0.9930(0.98,1.01)$ & 0.2709 \\
\hline ACT & beta coefficient & $P$-value \\
\hline
\end{tabular}




\begin{tabular}{|lll|}
\hline Outcome/variables & OR $(95 \% \mathrm{Cl})$ & $P$-value \\
\hline $\lg \mathrm{lg}$ & $0.0045(-0.03,0.04)$ & 0.8299 \\
\hline $\lg$ * Time & $0.0026(0.0008,0.004)$ & 0.0048 \\
\hline peripheral blood Eosinophil percentage & $0.0301(-0.056,0.116)$ & 0.4909 \\
\hline peripheral blood Eosinophil percentage * Time & $-0.0049(-0.009,-0.0002)$ & 0.0493 \\
\hline Time & $0.017(-0.011,0.045)$ & 0.2230 \\
\hline *: interaction between independent variable and time & \\
\hline
\end{tabular}

The blood eosinophil percentage was positively associated with asthma control (Table 2, OR $=1.0758, P$ $=0.0019)$. Asthma control is typically predictive of the risk of future exacerbations. A high blood eosinophil count was an independent risk factor for asthma exacerbations (32). There is a direct relationship between eosinophil count and the frequency of asthma exacerbations (that is, poor asthma control) (33). When the time effects and its interactions with peripheral blood eosinophil percentage (eosinophil $*$ time) were considered, the risk of poor asthma control increased 0.9968 -fold $(P=0.0068)$. Therefore, during follow-up, the higher the blood eosinophil percentage, the better the asthma control (protective effect). Recently, a high baseline blood eosinophil count is reportedly associated with better asthma control (34), which is in agree with our findings.

The association of asthma severity and asthma control with total serum IgE level was not significant. When the time effects and their interactions with total serum IgE level were considered (Table 2; IgE $*$ time), the risk of higher asthma severity and poorer asthma control increased 1.0014- and 1.0009-fold, respectively. There is reported to be an inverse association between serum total IgE and asthma control $(10,12)$. We suggest that the interaction between total serum IgE level and follow-up duration is predictive of long-term asthma severity and asthma control.

When the time effects and their interactions with total serum $\lg E(\lg E *$ time) were considered; for each unit increase in the total serum IgE level, the ACT score increased by 0.0026 unit $(P=0.0048)$. Therefore, during the follow-up, IgE level had a protective effect on the ACT score. When the time effects and their interactions with blood eosinophil percentage (eosinophils $*$ time) were considered, for each unit increase in blood eosinophil percentage, the ACT score decreased by 0.0049 unit $(P=0.0493)$. Therefore, during follow-up, the higher the blood eosinophil percentage, the lower the ACT score (risk effect). The ACT score is reported to be negatively correlated with the absolute eosinophil count (29).

Because both blood eosinophil percentage and their interaction with disease course (time) were related to asthma control, ACT, and PEF variability, we analyzed the validation cohort and verified the correlation of the blood eosinophil percentage and their interaction with disease course (time) with the five phenotype outcomes. The validation cohort comprised another 313 patients with eosinophil percentage data but without serum total IgE data. Their characteristics are compared to those of the 383 patients of the 
development cohort in supplemental Table 2 . Although the patients in the validation cohort had a slightly lower asthma severity than those in the development cohort, there was no significant difference in asthma control and ACT score between the two groups. Among the patients in the validation cohort, the blood eosinophil percentage and their interaction with disease course (time) were significantly associated with asthma control, ACT score, and PEF variability (supplemental Table 3), the same as in the development cohort.

\section{Association of ICS dosage with phenotype outcomes}

We evaluated the effect of controller treatment (ICS) on the outcome phenotype (Table 3). The predicted PEF (best percentage) was negatively associated with medium- and high-dose ICS (OR $=0.6061$ and 0.4609 , respectively [protective effect]). The effect of increasing ICS dose (medium $v s$ high) on the predicted PEF (standard percentage) was significant. Therefore, an increased ICS dose (step-up) is beneficial for predicted PEF (standard percentage). However, the PEF variability was positively associated with medium- and high-dose ICS (OR 1.4522 and 2.8937, respectively [risk effect]). An increased ICS dose (medium vs high) was significantly associated with greater PEF variability. According to GINA, after starting ICS, the personal best PEF is reached on average within 2 weeks. The average PEF continues to increase, and the PEF variability to decrease, for about 3 months (20). However, our clinical practice is to measure the PEF before the visit. The physician determines the ICS dose according the measured PEF at the outpatient clinic. In this retrospective analysis, the predicted PEF was negatively correlated with the ICS dose and the PEF variability was positively correlated with the ICS dose. In reality, the physician increases the ICS dose when the predicted PEF value decreases or when the PEF variability increases, and vice versa. 
Table 3

The association (ORs and beta coefficient) of inhaled corticosteroid dosage with phenotype outcomes under taking the time (disease duration) effect into account.

\begin{tabular}{|c|c|c|c|c|}
\hline \multirow[t]{2}{*}{ Phenotype Outcomes } & \multicolumn{2}{|l|}{ Univariate } & \multicolumn{2}{|l|}{ Multivariate $†$} \\
\hline & OR $(95 \% \mathrm{Cl}) \neq$ & $P$-value & OR $(95 \% \mathrm{Cl}) \neq$ & $P$-value \\
\hline \multicolumn{5}{|l|}{ Predicted PEF percentage } \\
\hline \multirow[t]{2}{*}{ High dose ICS } & 0.4609 & 0.0039 & 0.6399 & 0.3479 \\
\hline & $(0.2723,0.7801)$ & & $(0.2519,1.6252)$ & \\
\hline \multirow[t]{2}{*}{ Medium dose ICS } & 0.6061 & 0.0021 & 0.7069 & 0.1189 \\
\hline & $(0.4405,0.8340)$ & & $(0.4571,1.0931)$ & \\
\hline \multirow[t]{2}{*}{ High dose ICS $*$ Time } & n.a. & n.a. & 0.9809 & 0.3078 \\
\hline & & & $(0.9451,1.0180)$ & \\
\hline \multirow[t]{2}{*}{ Medium dose ICS $*$ Time } & n.a. & n.a. & 0.9902 & 0.3896 \\
\hline & & & $(0.9684,1.0126)$ & \\
\hline \multirow[t]{2}{*}{ Time } & n.a. & n.a. & 0.9937 & 0.3753 \\
\hline & & & $(0.9799,1.0077)$ & \\
\hline \multicolumn{5}{|l|}{ PEF variability } \\
\hline \multirow[t]{2}{*}{ High dose ICS } & 2.8937 & 0.0011 & 4.0392 & 0.0074 \\
\hline & $(1.5326,5.4635)$ & & $(1.4533,11.2265)$ & \\
\hline \multirow[t]{2}{*}{ Medium dose ICS } & 1.4522 & 0.0231 & 1.4595 & 0.1358 \\
\hline & $(1.0524,2.0037)$ & & $(0.8880,2.3987)$ & \\
\hline \multirow[t]{2}{*}{ High dose ICS $*$ Time } & n.a. & n.a. & 0.9762 & 0.1551 \\
\hline & & & $(0.9443,1.0092)$ & \\
\hline \multirow[t]{2}{*}{ Medium dose ICS $*$ Time } & n.a. & n.a. & 0.9962 & 0.8140 \\
\hline & & & $(0.9649,1.0284)$ & \\
\hline \multirow[t]{2}{*}{ Time } & n.a. & n.a. & 1.0153 & 0.0355 \\
\hline & & & $(1.0010,1.0298)$ & \\
\hline
\end{tabular}

*: interaction between independent variable and time

tAdjust for time effect.

¥Baseline: Low dose ICS 


\begin{tabular}{|c|c|c|c|c|}
\hline Phenotype Outcomes & Univariate & & Multivariate $†$ & \\
\hline \multicolumn{5}{|l|}{ Asthma severity } \\
\hline \multirow[t]{2}{*}{ High dose ICS } & 0.5452 & 0.0267 & 0.7518 & 0.5766 \\
\hline & $(0.3187,0.9325)$ & & $(0.2762,2.0465)$ & \\
\hline \multirow[t]{2}{*}{ Medium dose ICS } & 0.6069 & 0.0003 & 0.7614 & 0.2386 \\
\hline & $(0.4637,0.7945)$ & & $(0.4838,1.1982)$ & \\
\hline \multirow[t]{2}{*}{ High dose ICS $*$ Time } & n.a. & n.a. & 0.9724 & 0.1650 \\
\hline & & & $(0.9348,1.0116)$ & \\
\hline \multirow[t]{2}{*}{ Medium dose ICS $*$ Time } & n.a. & n.a. & 0.9786 & 0.2075 \\
\hline & & & $(0.9463,1.0120)$ & \\
\hline \multirow[t]{2}{*}{ Time } & n.a. & n.a. & 1.0164 & 0.0635 \\
\hline & & & $(0.9991,1.0340)$ & \\
\hline \multicolumn{5}{|l|}{ Asthma control } \\
\hline \multirow[t]{2}{*}{ High dose ICS } & 0.7847 & 0.4119 & 1.3774 & 0.5069 \\
\hline & $(0.4396,1.4004)$ & & $(0.5350,3.5464)$ & \\
\hline \multirow[t]{2}{*}{ Medium dose ICS } & 0.8376 & 0.2498 & 1.0294 & 0.8855 \\
\hline & $(0.6193,1.1327)$ & & $(0.6939,1.5272)$ & \\
\hline \multirow[t]{2}{*}{ High dose ICS $*$ Time } & n.a. & n.a. & 0.9702 & 0.1628 \\
\hline & & & $(0.9299,1.0123)$ & \\
\hline \multirow[t]{2}{*}{ Medium dose ICS $*$ Time } & n.a. & n.a. & 0.9897 & 0.3792 \\
\hline & & & $(0.9671,1.0128)$ & \\
\hline \multirow[t]{2}{*}{ Time } & n.a. & n.a. & 0.9776 & 0.0040 \\
\hline & & & $(0.9627,0.9928)$ & \\
\hline \multicolumn{5}{|l|}{ ACT } \\
\hline & beta coefficient & $P$-value & beta coefficient & $P$-value \\
\hline
\end{tabular}

*: interaction between independent variable and time †Adjust for time effect. ¥Baseline: Low dose ICS 


\begin{tabular}{|lllll|}
\hline Phenotype Outcomes & Univariate & \multicolumn{3}{l|}{ Multivariate † } \\
\hline High dose ICS & -1.1558 & 0.2497 & -0.4282 & 0.7867 \\
& $(-3.1342,0.8227)$ & & $(-3.5536,2.6973)$ & \\
\hline Medium dose ICS & -0.9044 & 0.0433 & -0.8995 & 0.1913 \\
& $(-1.7814,-0.02754)$ & & $(-2.2547,0.4558)$ & \\
\hline High dose ICS $*$ Time & n.a. & n.a. & -0.04412 & 0.5361 \\
& & & $(-0.1840,0.09572)$ & \\
\hline Medium dose ICS $*$ Time & n.a. & n.a. & -0.00377 & 0.9087 \\
& & & $(-0.06826,0.06072)$ & \\
\hline Time & n.a. & & $(-0.03017,0.07613)$ & \\
\hline *: interaction between independent variable and time & & 0.3966 \\
\hline †Adjust for time effect. & & & \\
\hline fBaseline: Low dose ICS & & & \\
\hline
\end{tabular}

Asthma severity was negatively associated with medium- and high-dose ICS (OR 0.6069 and 0.5452, respectively [protective effect]). The effect of an increased ICS dose on asthma severity was significant. Therefore, an increased ICS dose (medium vs high) is beneficial for reducing asthma severity. However, the effect of an increased ICS dose on improving asthma control was not significant $(P>0.05)$. By analyzing the ACT score, for each unit of increase in medium-dose ICS, the ACT score decreased by 0.9044 unit $(P=0.0433)$. Therefore, medium-dose ICS showed a negative linear association with the ACT score (risk effect). The effect of an increased ICS dose on decreasing the ACT score was not significant $(P>0.05)$.

When the time effects and their interactions with ICS dose were considered, the PEF variability was positively associated with high-dose ICS and follow-up duration (OR $=4.0392$ and 1.0153, respectively), reflecting the reactive measure by visiting physician to increased ICS dose when encountering the higher $P E F$ variability. For all phenotype outcomes, the interaction between disease course (time) and ICS dose was not significant. Interestingly, asthma control was negatively associated with follow-up duration (OR $=0.9776 ; P=0.0040$ ), indicating that follow-up (disease course) was a protective factor for asthma control under ICS treatment.

\section{Associations of total serum IgE level and peripheral blood eosinophil percentage with sensitization}


We used allergen sensitization status and comorbidities as outcomes and analyzed their associations with total serum IgE level and/or blood eosinophil percentage (supplemental Table 4). Because the allergen sensitization status was determined by measuring the allergen-specific IgE concentration, the reactions to all allergens were positively correlated with total serum IgE. In univariate analyses, the blood eosinophil percentage was associated with mite and dander/feather sensitization. The total serum IgE level but not the blood eosinophil percentage was associated with AR and/or AD.

\section{Comparison of childhood asthma according to total serum IgE level (allergic vs nonallergic)}

In our development cohort, there were 118 (30.81\%) children with nonallergic asthma (Table 1); nonallergic asthma reportedly occurs in $10-33 \%$ of individuals with asthma (27).

The proportion of nonallergic asthmatic patients with mild intermittent severity was similar to or smaller than that of the other two groups. However, the proportion of nonallergic asthmatic patients with mild persistent or moderate persistent severity was significantly larger or similar to that of the other two groups (two-way ANOVA $P=0.0012$ ) (Fig. 2). The proportion of nonallergic asthmatics with wellcontrolled level was equal to or slightly smaller than that of the other two groups. However, the proportion of nonallergic asthmatics with not well controlled and/or poorly controlled level was significantly larger than that of the other two groups (two-way ANOVA $P=0.0042$ ) (Fig. 3a). The average ACT score did not differ significantly among the three groups, irrespective of whether the patients had nonallergic or allergic asthma (Fig. 3b).

Allergic asthmatic patients had a higher frequency of a positive sensitization response than nonallergic asthmatic patients for all allergen classes. Interestingly, using a total serum IgE level of $<150 \mathrm{IU} / \mathrm{mL}$ as the cut-off for atopy, some nonallergic asthmatic patients had few allergen sensitization (supplemental Fig. 1). The proportion of asthma only or asthma plus AR was higher in nonallergic patients; however, most allergic asthmatic patients had $A D$ and/or AR plus AD (supplemental Fig. 2).

\section{Pattern of asthma severity changing with time according to total serum IgE level}

A majority of patients assigned to a specific asthma phenotype exhibit that same phenotype over a 10year period (54-88\%) (35). Among our long-term follow-up patients, those with a total IgE of 150$550 \mathrm{IU} / \mathrm{mL}$ (32 patients with 951 visits) and > $550 \mathrm{IU} / \mathrm{mL}$ (33 patients with 1154 visits) showed a stable pattern of asthma severity over the 10-year follow-up and showed annual improvement (Fig. 4). However, among patients with a total $\mathrm{lgE}$ of $<150 \mathrm{IU} / \mathrm{mL}$ (32 patients with 1095 visits), the average asthma severity was higher and intermittent attacks (increased severity) persisted. Similarly, Illi et al. reported that nonallergic patients showed more persistent wheezing symptoms than allergic patients after tracking for $>5$ years (36). Adults with nonallergic asthma have a less favorable prognosis than those with allergic asthma in terms of persistence of symptoms (37). 


\section{MicroRNA}

The heat map were generated by uploading the differential expressed miRNAs data between allergic and nonallergic asthma (supplement table V) to ClustVis (https://biit.cs.ut.ee/clustvis/). The expression levels of 135 miRNAs differed significantly between the two patient groups. Unsupervised hierarchical clustering of miRNA expression data revealed the formation of two major groups segregated based on the patients' disease status (Fig. 5a). These differentially expressed miRNAs could be classified into three pattern groups based on the differences in their expression between patients with allergic and nonallergic asthma. The expression levels of eight miRNAs were significantly decreased in allergic compared to nonallergic patients and that of one miRNA was significantly increased in allergic patients (q-value (38) 0.0 ; Fig. $5 b$ and supplemental Table 5), echoing the recent report of Weidner et al. (39). The expression level of miR-122-5p was significantly increased in patients with asthma (40). MiR-146a is reportedly upregulated in asthmatic children (41). The plasma level of miR-199a-5p is increased in neutrophilic asthma and is negatively correlated with pulmonary function (42). Bartel et al. reported the involvement of miR-144 in allergic airway inflammation (43). We identified 6 potential direct interaction pathways specific to $\lg E$ regulation for the top 8 differentially expressed miRNAs using ingenuity pathway analysis (IPA)(Fig. 5c).

\section{Discussion}

The identification of childhood asthma phenotype (asthma severity/asthma control) is important because: (i) the natural course of pediatric asthma is not fully characterized, (ii) the evaluation of asthma in children can be complicated by the difficulty in performing objective lung-function measurements, (iii) the lack of definitive biomarkers, (iv) it is unclear whether early intervention can alter the clinical course and phenotype outcome, and (v) longitudinal data are lacking (44). In this long-term follow-up study, childhood asthma exhibited at least two distinct phenotypes. First, the allergic type (total serum IgE of > $150 \mathrm{lU} / \mathrm{mL}$ ), in which the severity decreases gradually over 5-10 years. Second, the nonallergic type (total serum $\operatorname{lgE}$ of $<150 \mathrm{IU} / \mathrm{mL}$ ), in which the asthma severity is persistent and accompanied by paroxysmal deterioration. Such patients may experience relapses even after $5-10$ years.

The role of IgE is suggested by the fact that in allergic asthmatic patients the total serum and allergenspecific IgE levels are increased (45). In this study, some nonallergic asthmatic patients had allergen sensitization. Nonallergic asthma may also be distinguished from its allergic counterpart by the later age of onset and greater severity (46). However, the nonallergic asthmatic children in this study were significantly younger than those with allergic asthma, implying the existence of at least two age-related pathways. The mechanisms by which IgE signaling triggers the development and exacerbation of nonallergic asthma are unclear (46). We showed that compared to nonallergic patients, the expression levels of miR-100-5p, miR-144-5p, miR-146a-5p, miR-150-5p, miR-151a-5p, miR-199a-3p, and miR-374b-5p were significantly decreased in allergic asthma and that of miR-122-5p was significantly increased in allergic patients. Our data suggest that the lack of atopy (nonallergic) plays a potential role in modulating the effect of a variety of factors on the expression of asthma phenotype (27) and that some factors are 
involved in the different reactivity to IgE between allergic and nonallergic asthma (46). According to Siroux et al., allergic children had a significantly milder asthma compared to nonallergic children (mean severity score 1.1 vs. 1.9, respectively) (5). Adult patients with severe asthma had less atopy (47). However, total serum IgE is rarely measured in the diagnosis of human allergic disease. The high upper limits of normal and broad overlap between IgE concentrations in allergic and nonallergic people limit the diagnostic value of total serum IgE measurements for allergic disease. With the licensing of anti-lgE therapy for the treatment of IgE-dependent asthma, there has been a minor resurgence in the clinical measurement of total serum IgE (48). The value of total serum IgE measurement suggests a predictive role for IgE in modulating asthma severity.

The GINA guidelines and multiple large-scale clinical trials have helped to guide current evidence-based treatments (20). The current stepwise therapeutic approach is designed to maximize the overall level of asthma control and medication compliance. There is the following consensus on the natural history of asthma. In general, symptoms can begin at any age, although the type of asthma that predominates in those with onset as children, teenagers, and adults may differ. Over time, the symptoms of asthma can remit in any patient, especially in children (49). Alternatively, the symptoms and the finding of airflow obstruction can persist or even worsen progressively in some patients. Taking into account the fact that all of the patients in this study had received guideline-based management, and the differences in age at disease onset, we compared the pattern of asthma severity change during a 5-15-year follow-up period. This natural history measurement is similar to the real-world situation. The finding of a strong association between ICS use at baseline and more severe asthma 9 years later suggests that the ability of treatment to modify asthma severity is limited (50). Randomized placebo-controlled trials have not found that ICS treatment during the preschool years alters the natural history of asthma $(51,52)$. Notably, the clinical pattern of greater asthma severity in the difficult-to-control group occurred despite sustained use of the highest step levels of guideline-based asthma controllers over the course of the year (12). From our data that the association of ICS dose with all five phenotype outcomes during long-term follow-up were not significant, we suggest that guideline-based and manager-guided asthma care do not alter the long-term disease course or phenotype outcomes of childhood asthma. It is possible that total serum IgE level and blood eosinophil percentage have a considerable influence on the disease course and phenotype outcome of asthma.

As recommended by EPR-3, PEF is a valuable, easily available measurement, well suited for monitoring trends in asthma control over time in children age 4 years and older, but less useful in diagnosing asthma or classifying its severity (22). Indeed, $\mathrm{FEV}_{1}$ does not correlate well with the magnitude of asthma symptoms in children (53). We here considered PEF as an alternative objective lung function measurement for children with asthma. We showed that the peripheral blood eosinophil percentage and its interactions with time influenced both PEF variability and asthma control. In this study, both predicted PEF percentage and PEF variability were not associated with serum total IgE or its interactions with time. In children with atopic asthma sensitized to house-dust mite, the serum IgE level reflects that of markers of allergic inflammation but not pulmonary volume or the degree of airflow limitation (54). A baseline 
high blood eosinophil count is reportedly associated with better asthma control (34). The mean PEF is significantly and negatively correlated with the blood eosinophil count (55). Increases in the sputum eosinophil count are correlated with decreases in morning PEF and loss of asthma control (16). There is a correlation between the blood eosinophil count and those in the lower airway (sputum, BAL, lungs tissue) (56). We suggest that serum IgE is involved in the allergic and nonallergic inflammatory cascade, but blood eosinophilia is a consequence of systemic inflammation and reflects pulmonary function or the degree of airflow limitation $(45,54)$.

\section{Conclusions}

We suggest that total serum IgE level is predictive of long-term asthma severity and asthma control. We demonstrated the blood eosinophil percentage were associated with long-term asthma control, ACT score, and PEF variability. For all phenotype outcomes, we showed that follow-up duration was a protective factor for asthma control under ICS treatment. Allergic asthma showed a stable pattern of asthma severity over the 10-year follow-up while in nonallergic patients, the average asthma severity was higher and intermittent attacks (increased severity) persisted. The expression of certain miRNAs were significantly different in allergic asthma compared to nonallergic patients. We suggest that total serum IgE might be involved in modulating disease severity of both allergic and nonallergic asthma while peripheral blood eosinophilia reflects the status of longitudinal lung function.

\section{Abbreviations}

PEF: peak expiratory flow; ACT:asthma control test; GEEs:generalized estimating equations; GINA:Global Initiative for Asthma; ICS:inhaled corticosteroids.

\section{Declarations}

\section{Ethics approval and consent to participate:}

This study was approved by the Institutional Review Board and Research Ethics Committee of the National Taiwan University Hospital and was conducted in compliance with the protocol for good clinical practices and the principles of the Declaration of Helsinki. The written informed consents were obtained from all participants and/or their legal guardians.

\section{Consent for publication:}

Not applicable.

\section{Availability of data and materials:}


All data generated or analysed during this study are included in this published article [and its supplementary information files].

\section{Competing interests:}

The authors declare that they have no competing interests.

\section{Funding:}

The authors declare that they have no funding.

\section{Authors' contributions:}

Conception and design of the studies: J-H Lee and B-L Chiang. Executed the studies and acquired the data: A-L Chu, S-Y Hsiao, and K-Y Chang. Analyzed and interpreted the data. J-H Lee, Y-H Yang, Y-T Lin, L$\mathrm{C}$ Wang, $\mathrm{H}-\mathrm{H} \mathrm{Yu}$, and $\mathrm{Y}-\mathrm{C} \mathrm{Hu}$. Wrote the manuscript draft, which was reviewed and revised by all authors: $\mathrm{J}-\mathrm{H}$ Lee. All authors reviewed and approved the final manuscript.

\section{Acknowledgements:}

We thank both Dr. Chin-Hao Chang, Ying-Ting Chao and Tse-Le Huang from Department of Medical Research, National Taiwan University Hospital, for invaluable assistance with statistical consultation, analysis and model development/validation.

\section{References}

1. Wenzel SE. Asthma phenotypes: the evolution from clinical to molecular approaches. Nature medicine. 2012;18(5):716-25.

2. Marsh DG, Bias WB, Ishizaka K. Genetic control of basal serum immunoglobulin E level and its effect on specific reaginic sensitivity. Proc Natl Acad Sci USA. 1974;71(9):3588-92.

3. Woodruff PG, Modrek B, Choy DF, Jia G, Abbas AR, Ellwanger A, et al. T-helper type 2-driven inflammation defines major subphenotypes of asthma. Am J Respir Crit Care Med. 2009;180(5):388-95.

4. Ahlstedt S, Murray CS. In vitro diagnosis of allergy: how to interpret IgE antibody results in clinical practice. Primary Care Respiratory Journal. 2006;15(4):228-36.

5. Siroux V, Oryszczyn MP, Paty E, Kauffmann F, Pison C, Vervloet D, et al. Relationships of allergic sensitization, total immunoglobulin $\mathrm{E}$ and blood eosinophils to asthma severity in children of the EGEA Study. Clinical experimental allergy: journal of the British Society for Allergy Clinical Immunology. 2003;33(6):746-51. 
6. Kovac K, Dodig S, Tjesic-Drinkovic D, Raos M. Correlation between asthma severity and serum IgE in asthmatic children sensitized to Dermatophagoides pteronyssinus. Arch Med Res. 2007;38(1):99105.

7. Borish L, Chipps B, Deniz Y, Gujrathi S, Zheng B, Dolan CM. Total serum IgE levels in a large cohort of patients with severe or difficult-to-treat asthma. Annals of allergy, asthma \& immunology: official publication of the American College of Allergy. Asthma Immunology. 2005;95(3):247-53.

8. Carroll WD, Lenney W, Child F, Strange RC, Jones PW, Whyte MK, et al. Asthma severity and atopy: how clear is the relationship? Archives of disease in childhood. 2006;91(5):405-9.

9. Fitzpatrick AM, Teague WG, Meyers DA, Peters SP, Li X, Li H, et al. Heterogeneity of severe asthma in childhood: confirmation by cluster analysis of children in the National Institutes of Health/National Heart, Lung, and Blood Institute Severe Asthma Research Program. The Journal of allergy and clinical immunology. 2011;127(2):382-9.e1-13.

10. Howrylak JA, Fuhlbrigge AL, Strunk RC, Zeiger RS, Weiss ST, Raby BA. Classification of childhood asthma phenotypes and long-term clinical responses to inhaled anti-inflammatory medications. J Allergy Clin Immunol. 2014;133(5):1289-300. 300.e1-12.

11. Naqvi M, Choudhry S, Tsai HJ, Thyne S, Navarro D, Nazario S, et al. Association between IgE levels and asthma severity among African American, Mexican, and Puerto Rican patients with asthma. J Allergy Clin Immunol. 2007;120(1):137-43.

12. Pongracic JA, Krouse RZ, Babineau DC, Zoratti EM, Cohen RT, Wood RA, et al. Distinguishing characteristics of diffıcult-to-control asthma in inner-city children and adolescents. J Allergy Clin Immunol. 2016;138(4):1030-41.

13. Zoratti EM, Krouse RZ, Babineau DC, Pongracic JA, O'Connor GT, Wood RA, et al. Asthma phenotypes in inner-city children. J Allergy Clin Immunol. 2016;138(4):1016-29.

14. Kamfar HZ, Koshak EE, Milaat WA. Is there a role for automated eosinophil count in asthma severity assessment? The Journal of asthma: official journal of the Association for the Care of Asthma. 1999;36(2):153-8.

15. Casciano J, Krishnan JA, Small MB, Buck PO, Gopalan G, Li C, et al. Value of peripheral blood eosinophil markers to predict severity of asthma. BMC pulmonary medicine. 2016;16(1):109.

16. Jatakanon A, Lim S, Barnes PJ. Changes in sputum eosinophils predict loss of asthma control. Am J Respir Crit Care Med. 2000;161(1):64-72.

17. Ulrik CS. Peripheral eosinophil counts as a marker of disease activity in intrinsic and extrinsic asthma. Clinical experimental allergy: journal of the British Society for Allergy Clinical Immunology. 1995;25(9):820-7.

18. Saglani S, Lloyd CM. Eosinophils in the pathogenesis of paediatric severe asthma. Curr Opin Allergy Clin Immunol. 2014;14(2):143-8.

19. Lang A, Mowinckel P, Sachs-Olsen C, Riiser A, Lunde J, Carlsen KH, et al. Asthma severity in childhood, untangling clinical phenotypes. Pediatric allergy immunology: official publication of the European Society of Pediatric Allergy Immunology. 2010;21(6):945-53. 
20. Hogan AD, Bernstein JA. GINA updated 2019: Landmark changes recommended for asthma management. Annals of allergy, asthma \& immunology: official publication of the American College of Allergy. Asthma Immunology. 2020;124(4):311-3.

21. Liu AH, Zeiger R, Sorkness C, Mahr T, Ostrom N, Burgess S, et al. Development and cross-sectional validation of the Childhood Asthma Control Test. J Allergy Clin Immunol. 2007;119(4):817-25.

22. Expert Panel Report 3 (EPR-3). Guidelines for the Diagnosis and Management of Asthma-Summary Report 2007. J Allergy Clin Immunol. 2007;120(5 Suppl):94-138.

23. Pedersen S. Measuring childhood asthma control. J Allergy Clin Immunol. 2014;133(6):1606-7.

24. Lugogo N, Que LG, Gilstrap DL, Kraft M. Asthma: clinical diagnosis and management. Murray and Nadel's Textbook of Respiratory Medicine: Elsevier; 2016. p. 731 - 50. e7.

25. Liang K-Y, Zeger SL. Longitudinal data analysis using generalized linear models. Biometrika. 1986;73(1):13-22.

26. Motulsky H, Christopoulos A. Fitting models to biological data using linear and nonlinear regression: a practical guide to curve fitting: Oxford University Press; 2004.

27. Peters SP. Asthma phenotypes: nonallergic (intrinsic) asthma. The journal of allergy clinical immunology In practice. 2014;2(6):650-2.

28. Haughney J, Morice A, Blyth KG, Lee AJ, Coutts A, McKnight E, et al. A retrospective cohort study in severe asthma describing commonly measured biomarkers: Eosinophil count and IgE levels. Respiratory medicine. 2018;134:117-23.

29. Arango SA, Toh J, Ferastraoaru D, de Vos G, Rosenstreich DL, Jariwala SP. Association between asthma control test, peripheral eosinophil counts, and serum total immunoglobulin $E$ levels in severe asthmatics. Journal of Allergy Clinical Immunology. 2016;137(2):AB206.

30. Rosario CS, Cat ML, Neto HJC, Riedi CA, Rosario NA. Eosinophil Counts and Asthma Severity in Children. Journal of Allergy Clinical Immunology. 2017;139(2):AB200.

31. Doi S, Murayama N, Inoue T, Takamatsu I, Kameda M, Omoto Y, et al. CD4 T-lymphocyte activation is associated with peak expiratory flow variability in childhood asthma. J Allergy Clin Immunol. 1996;97(4):955-62.

32. Zeiger RS, Schatz M, Dalal AA, Chen W, Sadikova E, Suruki RY, et al. Blood Eosinophil Count and Outcomes in Severe Uncontrolled Asthma: A Prospective Study. The journal of allergy clinical immunology In practice. 2017;5(1):144 - 53.e8.

33. Price DB, Rigazio A, Campbell JD, Bleecker ER, Corrigan CJ, Thomas M, et al. Blood eosinophil count and prospective annual asthma disease burden: a UK cohort study. The Lancet Respiratory medicine. 2015;3(11):849-58.

34. Goyal JP, Kumar P, Singh S. Association of Blood Eosinophil and Neutrophil with Asthma Control in Children. Eur Respiratory Soc; 2019.

35. Boudier A, Curjuric I, Basagaña X, Hazgui H, Anto JM, Bousquet J, et al. Ten-Year Follow-up of Cluster-based Asthma Phenotypes in Adults. A Pooled Analysis of Three Cohorts. Am J Respir Crit 
Care Med. 2013;188(5):550-60.

36. Illi S, von Mutius E, Lau S, Niggemann B, Gruber C, Wahn U. Perennial allergen sensitisation early in life and chronic asthma in children: a birth cohort study. Lancet. 2006;368(9537):763-70.

37. Amelink M, de Nijs SB, Berger M, Weersink EJ, ten Brinke A, Sterk PJ, et al. Non-atopic males with adult onset asthma are at risk of persistent airflow limitation. Clinical experimental allergy: journal of the British Society for Allergy Clinical Immunology. 2012;42(5):769-74.

38. Storey JD, Tibshirani R. Statistical significance for genomewide studies. Proc Natl Acad Sci USA. 2003;100(16):9440-5.

39. Weidner J, Ekerljung L, Malmhäll C, Miron N, Rådinger M. Circulating microRNAs correlate to clinical parameters in individuals with allergic and non-allergic asthma. Respiratory research. 2020;21(1):107.

40. Bahmer T, Krauss-Etschmann S, Buschmann D, Behrends J, Watz H, Kirsten AM, et al. RNA-seq-based profiling of extracellular vesicles in plasma reveals a potential role of miR-122-5p in asthma. Allergy. 2020.

41. Hammad Mahmoud Hammad R, Hamed D, Eldosoky M, Ahmad A, Osman HM, Abd Elgalil HM, et al. Plasma microRNA-21, microRNA-146a and IL-13 expression in asthmatic children. Innate immunity. 2018;24(3):171-9.

42. Huang Y, Zhang S, Fang X, Qin L, Fan Y, Ding D, et al. Plasma miR-199a-5p is increased in neutrophilic phenotype asthma patients and negatively correlated with pulmonary function. PloS one. 2018;13(3):e0193502.

43. Bartel S, Schulz N, Alessandrini F, Schamberger AC, Pagel P, Theis FJ, et al. Pulmonary microRNA profiles identify involvement of Creb1 and Sec14I3 in bronchial epithelial changes in allergic asthma. Scientific reports. 2017;7:46026.

44. Guilbert TW, Lemanske RF Jr, Jackson DJ. Diagnosis of asthma in infants and children. Middleton's Allergy: Elsevier; 2014. pp. 861-75.

45. Matucci A, Vultaggio A, Maggi E, Kasujee I. Is IgE or eosinophils the key player in allergic asthma pathogenesis? Are we asking the right question? Respiratory research. 2018;19(1):113.

46. Froidure A, Mouthuy J, Durham SR, Chanez P, Sibille Y, Pilette C. Asthma phenotypes and IgE responses. Eur Respir J. 2016;47(1):304-19.

47. Moore WC, Bleecker ER, Curran-Everett D, Erzurum SC, Ameredes BT, Bacharier L, et al. Characterization of the severe asthma phenotype by the National Heart, Lung, and Blood Institute's Severe Asthma Research Program. J Allergy Clin Immunol. 2007;119(2):405-13.

48. Hamilton RG. Laboratory tests for allergic and immunodeficiency diseases. Middleton's Allergy: Principles and Practice: Eighth Edition: Elsevier Inc.; 2013. p. 1187 - 204.

49. Woodruff PG, Bhakta NR, Fahy JV. Asthma: pathogenesis and phenotypes. Murray and Nadel's textbook of respiratory medicine: Elsevier; 2016. p. 713 - 30. e7. 
50. de Marco R, Marcon A, Jarvis D, Accordini S, Almar E, Bugiani M, et al. Prognostic factors of asthma severity: a 9-year international prospective cohort study. J Allergy Clin Immunol. 2006;117(6):124956.

51. Guilbert TW, Morgan WJ, Zeiger RS, Mauger DT, Boehmer SJ, Szefler SJ, et al. Long-term inhaled corticosteroids in preschool children at high risk for asthma. N Engl J Med. 2006;354(19):1985-97.

52. Lee-Sarwar KA, Bacharier LB, Litonjua AA. Strategies to alter the natural history of childhood asthma. Curr Opin Allergy Clin Immunol. 2017;17(2):139-45.

53. Sharek PJ, Mayer ML, Loewy L, Robinson TN, Shames RS, Umetsu DT, et al. Agreement among measures of asthma status: a prospective study of low-income children with moderate to severe asthma. Pediatrics. 2002;110(4):797-804.

54. Sacco O, Sale R, Silvestri M, Serpero L, Sabatini F, Raynal ME, et al. Total and allergen-specific IgE levels in serum reflect blood eosinophilia and fractional exhaled nitric oxide concentrations but not pulmonary functions in allergic asthmatic children sensitized to house dust mites. Pediatric allergy immunology: official publication of the European Society of Pediatric Allergy Immunology. 2003;14(6):475-81.

55. Griffın E, Håkansson L, Formgren H, Jörgensen K, Peterson C, Venge P. Blood eosinophil number and activity in relation to lung function in patients with asthma and with eosinophilia. J Allergy Clin Immunol. 1991;87(2):548-57.

56. Tashkin DP, Wechsler ME. Role of eosinophils in airway inflammation of chronic obstructive pulmonary disease. Int J Chronic Obstr Pulm Dis. 2018;13:335-49.

\section{Figures}




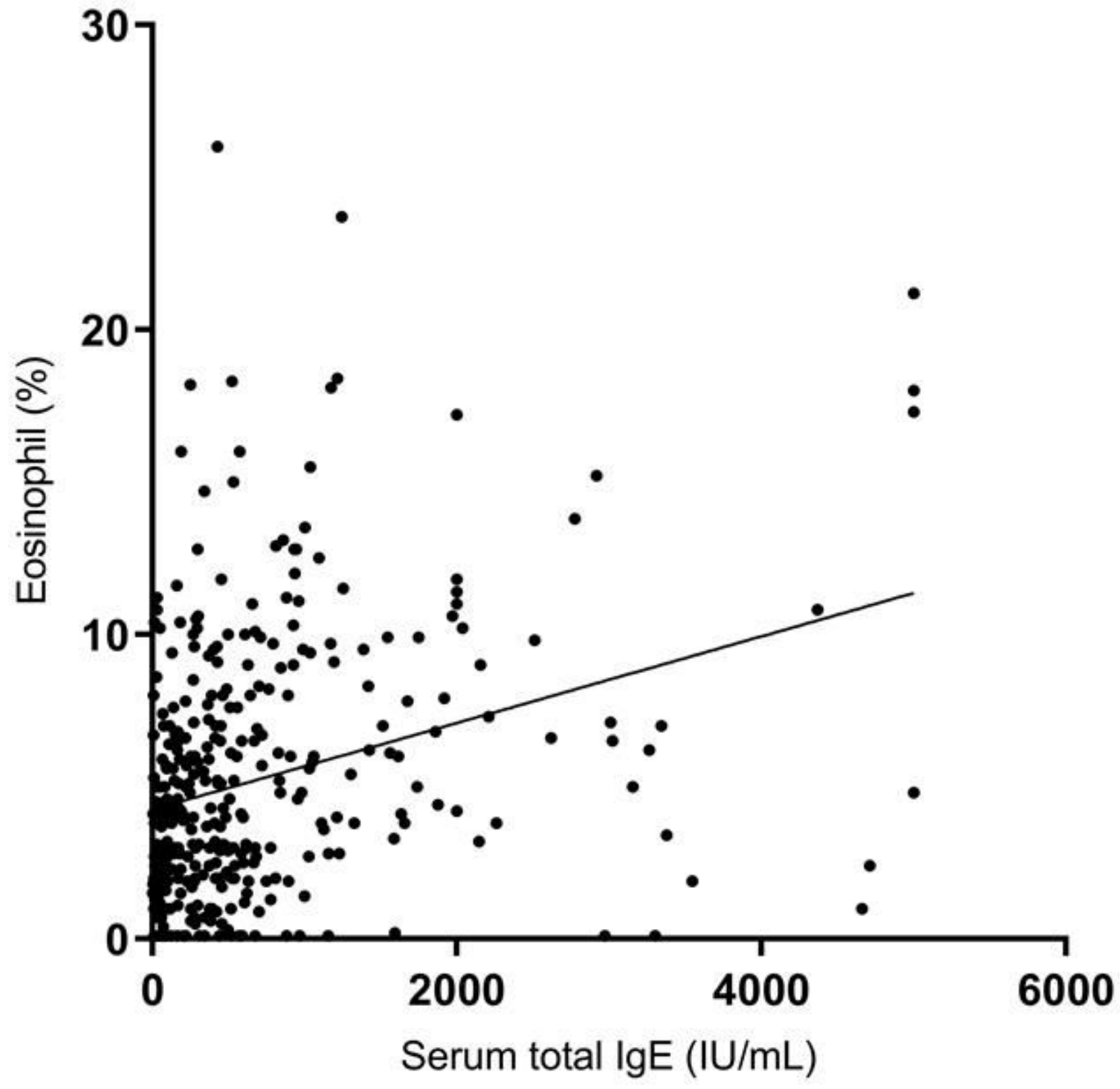

Figure 1

Correlation between total serum IgE level and peripheral blood eosinophil percentage. Pearson's $r=$ $0.34725, \mathrm{P}<0.0001$. 
Two-way ANOVA $P=0.0012$

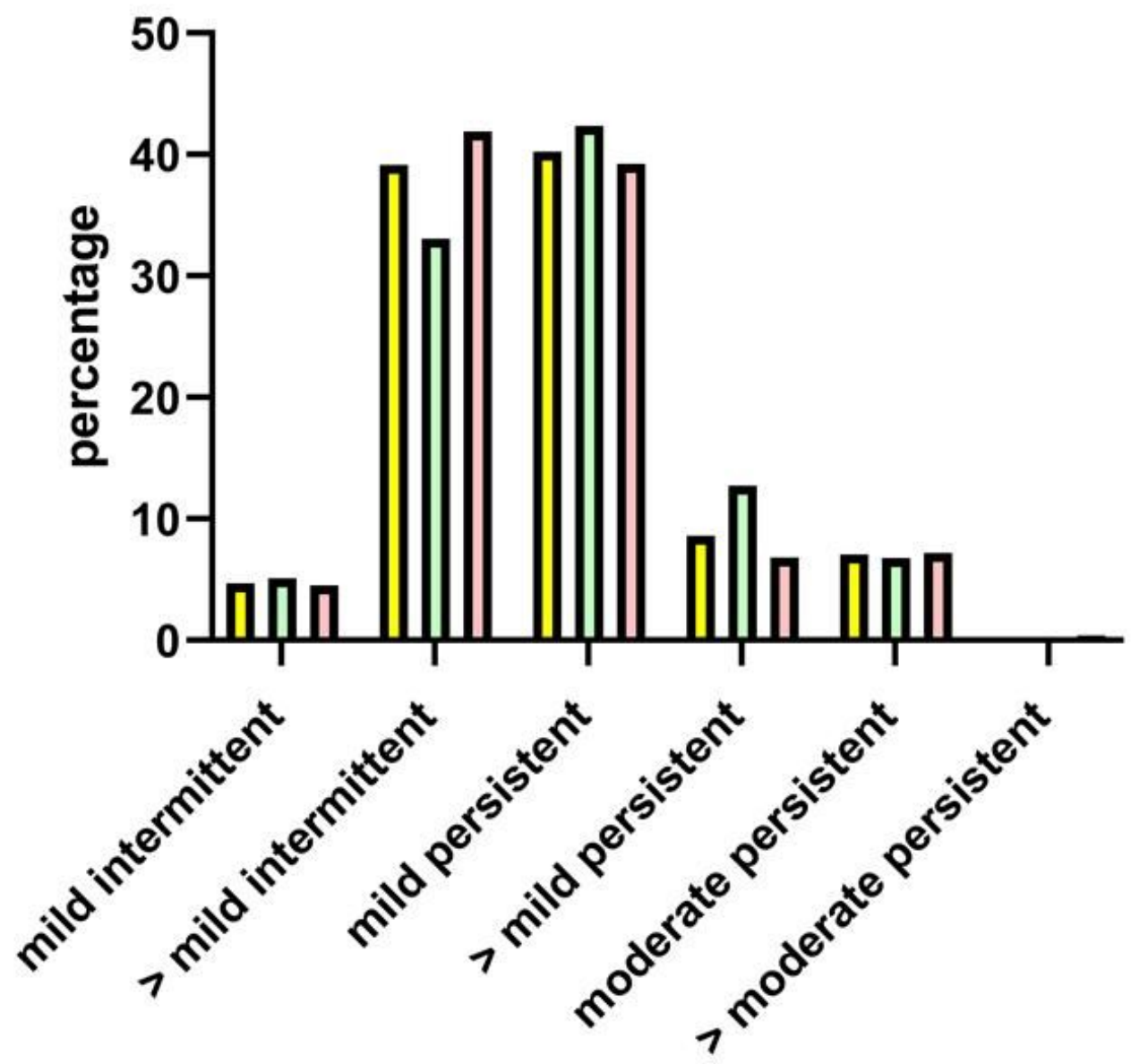

$\square$ total subjects

$\square$ nonallergics

口 allergics

Figure 2

Comparison of asthma severity between total subjects $(n=383)$, nonallergic asthma $(n=118)$ and allergic asthma groups $(n=265)$. Asthma severity were classified as: intermittent, mild persistent, moderate persistent, and severe persistent. 
A

Two-way ANOVA $P=0.0042$

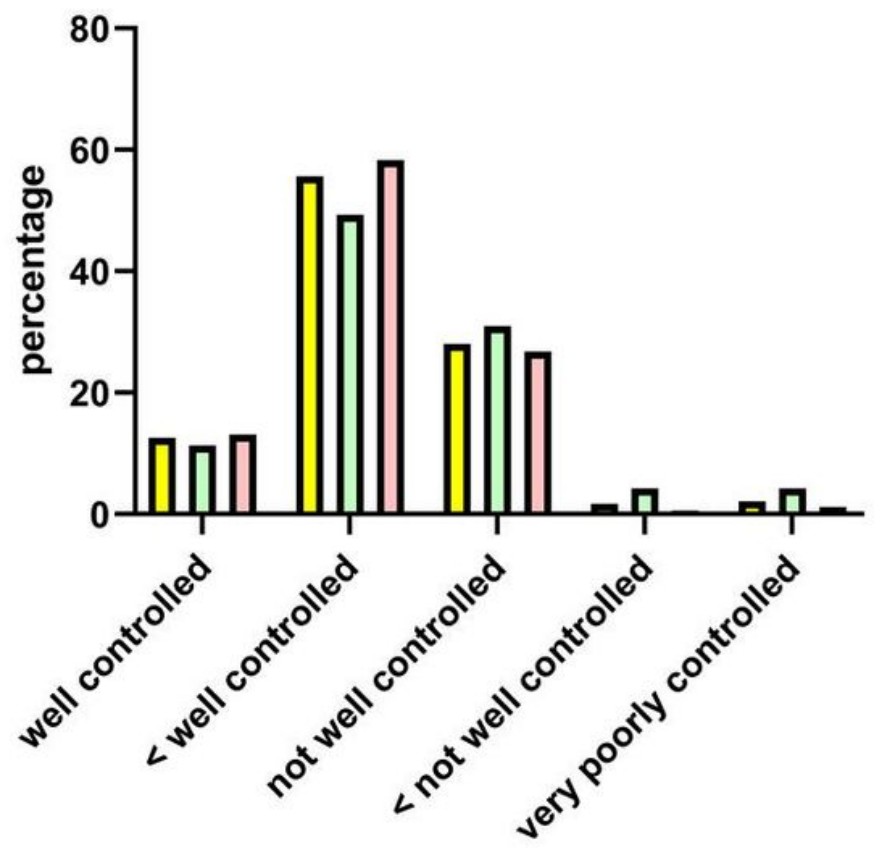

B

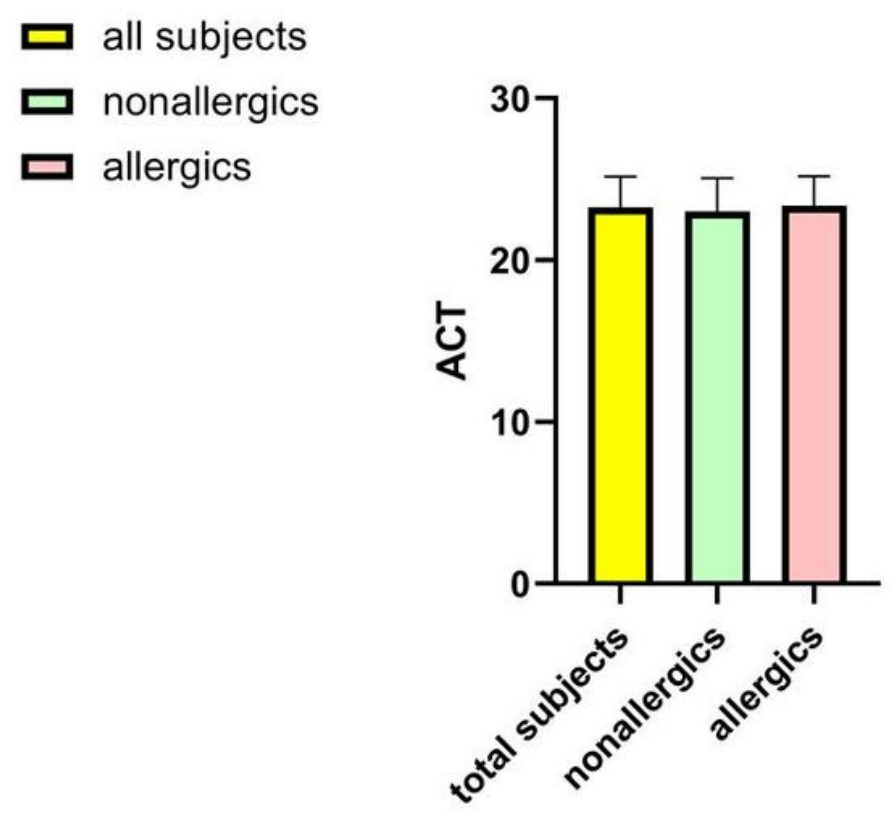

Figure 3

(a) Comparison of asthma control (a) and ACT score (b) between total subjects $(n=383)$, nonallergic asthma $(n=118)$ and allergic asthma groups $(n=265)$. Asthma control were classified as: well controlled (1 point), not well controlled ( 2 point) and very poorly controlled (3 point).

(a)

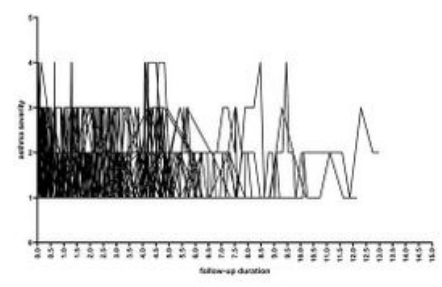

(c)

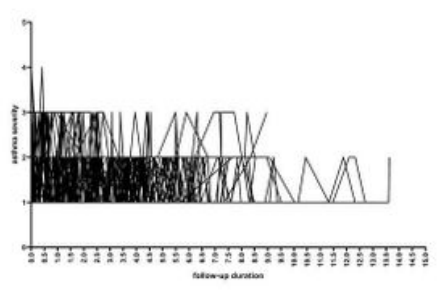

(b)
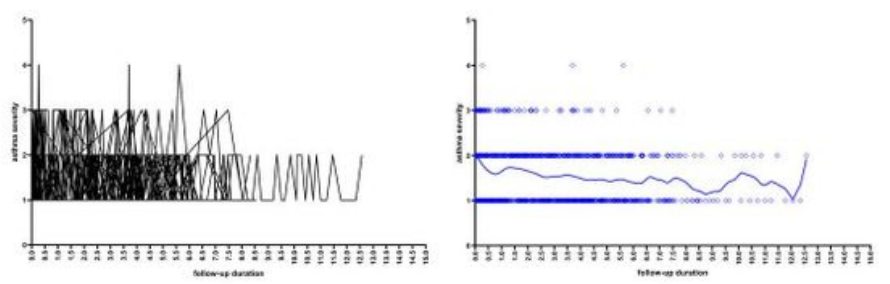

(d)

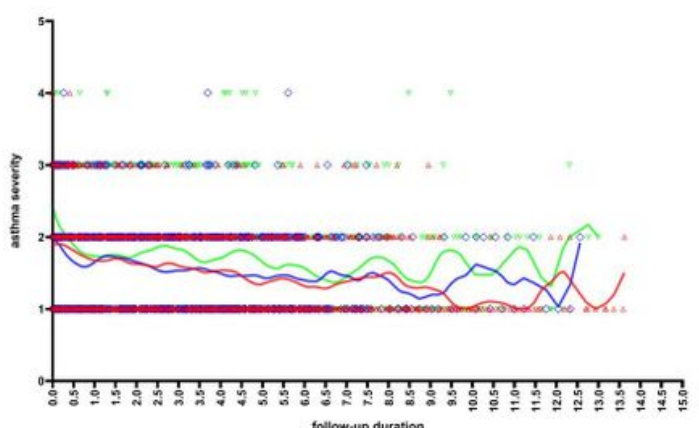




\section{Figure 4}

Analysis of the association between follow-up duration and the asthma severity performed by applying a Locally Weighted Scatterplot Smoother (LOWESS) to the patients with serum total $\operatorname{lgE}<150 \mathrm{IU} / \mathrm{mL}$ (a; green color, $\mathrm{n}=32$ ), IgE 150-550 mL (b; blue color, $\mathrm{n}=32$ ) and IgE> $550 \mathrm{~mL}$ (c; red color, $\mathrm{n}=33$ ) and all subjects ( $d$; merged, $n=97)$ by drawing a line through the central tendency of the asthma severity changing with time. All the individual data points representing asthma severity at each follow-up visit from each subject were connected with line and shown on left figure of (a), (b), (c). The fitted line is a LOWESS smoother (right figure).

(a)

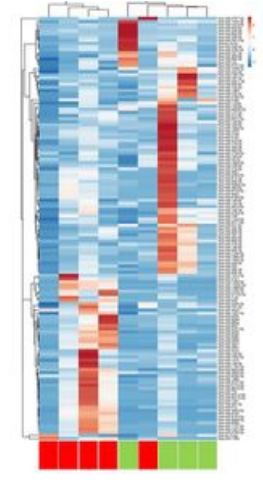

(b)

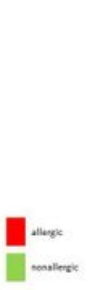

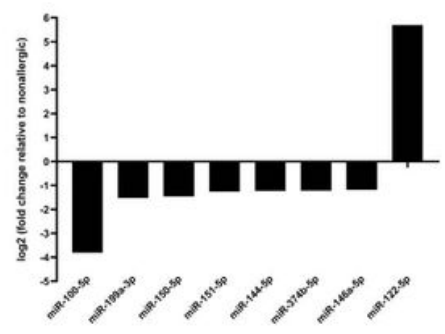

(c)

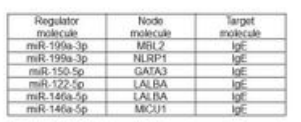

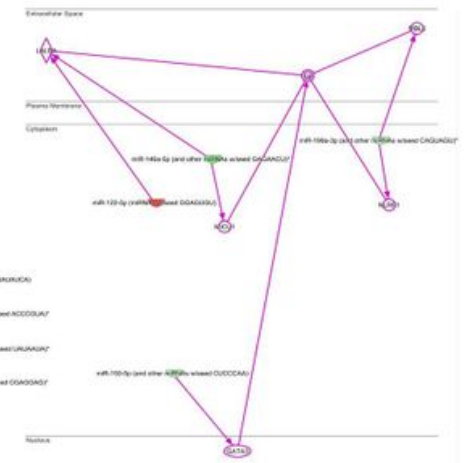

\section{Figure 5}

miRNA expression in both allergic and nonallergic asthmatic subjects. (a) Heatmap showing expression of 135 miRNAs in 5 allergic and 4 nonallergic asthmatic subjects after 2-way unsupervised hierarchical clustering. (b) Differential expression levels of 8 miRNAs between allergic and nonallergic asthmatic patients. (c) IgE regulation pathways implied by target mRNA molecules of differentially expressed miRNAs between allergic and nonallergic asthma predicted by ingenuity pathway analysis (IPA). The 6 direct interaction pathway networks are presented here. Red indicates increased expression relative to nonallergic asthma, and green indicates predicted decreased expression.

\section{Supplementary Files}

This is a list of supplementary files associated with this preprint. Click to download.

- supplementTables.docx

- supplementFigure1 sensitization.tif

- supplementFigure2comobidity.tif 